\title{
Assessment of the Ortachala HPP low head dam abutment deformation and seepage regime
}

\author{
Mirian Kalabegishvili ${ }^{1}$, Levan Klimiashvili ${ }^{1}$, David Gurgenidze ${ }^{1}$, and Adam Ujma $^{2, *}$ \\ ${ }^{1}$ Georgian Technical University, 68 M.Kostava St. 0175 Tbilisi, Georgia \\ ${ }^{2}$ Czestochowa University of Technology, Faculty of Civil Engineering, ul. Akademicka 3, \\ 42-200 Czestochowa
}

\begin{abstract}
During Ortachala HPP operation period cracks were formed in the right-bank of foundation, where is located underground fish-way sections. Right bank dam-foundation contact opened only in the horizontal direction, that caused $5.5 \mathrm{~cm}$ gap development, while there were no changes in the vertical direction. Visual researches showed that cracks (size is 4-5 cm) developed in fish-way construction. Mathematical models: fish-drainage-foundation, retaining wall-drainage-foundation, with the use of the finite element scheme, allowed us to finalize the suffusiondeformation process developed during the operation, namely: in the cracking zones of fish-way developed high gradients of seepage pressure, causing suffusion; under the influence of the weight of the soil and transport, shrinkage of the soil developed, which for the foundation of the right bank, created bending deformations causing the rotation of the soil in the vertical plane; bending deformation of the foundation at the contact of the concrete structure and the embankment caused a horizontal opening, spread out - at a depth of $4 \mathrm{~m}$. In connection with this, the retaining wall, leaning against the ground, loses support and, under the influence of hydrostatic pressure, tensile stress develops in it. In the case of crack formation in the wall, concentrated seepage will develop, which will cause groundwater rise in the main road and various unfavourable processes. Having established the reason for opening the contact, the fish was closed, as a result of which above mentioned process was stopped. Thus, the waterproofing of the fish-way is a necessary measure for the normal operation of the waterworks.
\end{abstract}

\section{Introduction}

Ortachala HPP is the law head waterworks facility situated in central part of Tbilisi. Station is being operated since 1955. Reservoir, placed in river canyon, is surrounded by on both sides, with underground draining galleries behind them. The latter is purposed (by design) to avoid rising of groundwater table level on banks that may cause flooding of the city communication lines (public systems, cable-lines and etc.), deformation of the road surface and development of other subsequent unfavorable processes. On the right-bank is also situated under ground fish-way sections (Fig. 1, photos 1,2).

*Corresponding author: aujma55@,wp.pl 
During operation period cracks were formed in the right-bank foundation in HPP and under ground fish-way sections. Surprisengly, right bank dam-foundation contact opened only in the horizontal direction, that caused $5.5 \mathrm{~cm}$ gap development, while there were no changes in the vertical direction. Visual reaseraches showed that cracks developed in fish-way construction. Gap size is $4-5 \mathrm{~cm}$. Some results of deformation and seepage developed analysis in right bank foundation is given below.

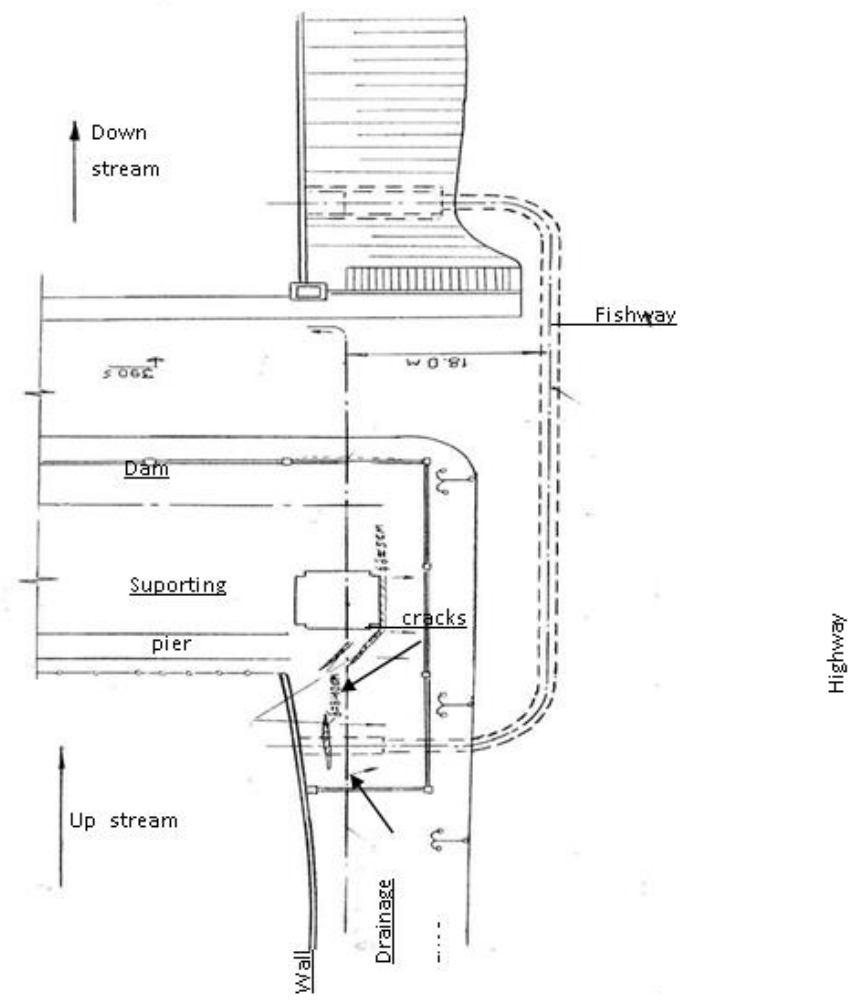

Fig. 1. Cracks developed in Ortachala HPP right bank.

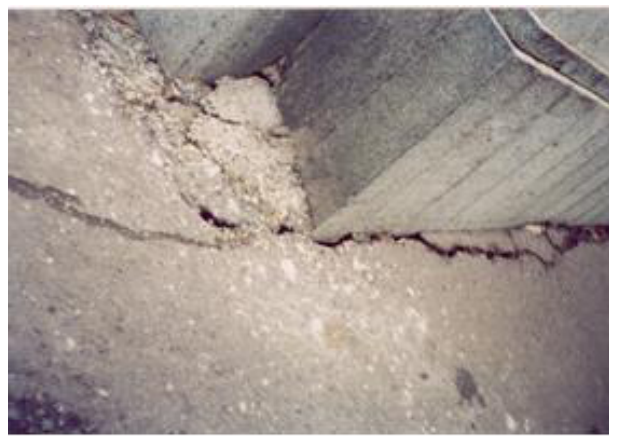

Photo 1. Cracks developed in Ortachala HPP right bank.

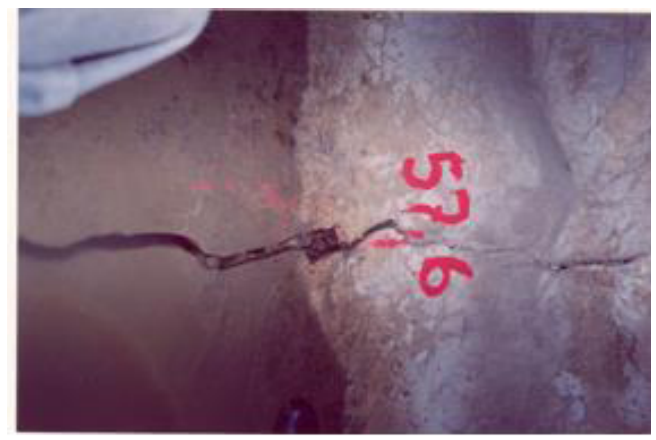

Photo 2. Cracks developed in under ground fish-way. 


\section{Mathematical model of seepage-deformation proses}

Seepage regime and deforamtions, developed in water bank, are interconnected processes. Exact estimation of the task requires seepage and static calculation review of the "fish-way - drainage - foundation" system.

Generally, pressure-free seepage task is reviewed. Above mentioned considers depression surface unknown outline and seepage flow parameters definition. Calculations are based on second row differential equation solution considering anisotropic massive:

$$
\frac{\partial}{\partial x}\left(K_{x} \frac{\partial H}{\partial x}\right)+\frac{\partial}{\partial y}\left(K_{y} \frac{\partial H}{\partial y}\right)+Q=0
$$

where: $H$ - is a pressure, $K_{x}$ and $K_{y}$ are hydraulic conductivity in the direction of $x$ and $y$ axis; accordingly, $Q$ - is seepage flow discharge.

On base of presented differential equation, with finite element method usage, in condition of system seepage flow total potential energy minimization, task shall be solved. Calculations were held with iteration scheme (Fig. 2). By choosing step, high degree of convergence shall be achieved.

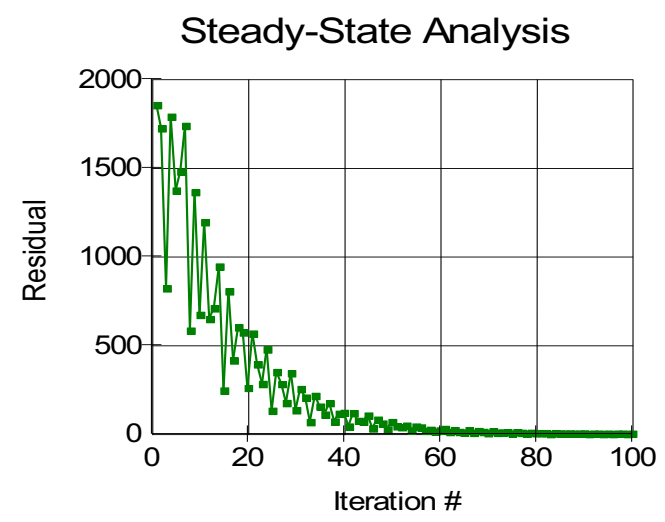

Fig. 2. Cycle - iteration scheme of calculation.

Fish-way, that is totally located in the embankment, in the process of operation was compacted with soil. In the result, along it's longitudinal axis, cross cracks were developed in the construction (especially in the bottom), that itself caused seepage. Generally, soil seepage strength condition has it's faces:

$$
J<J_{c r}
$$

where: $J$ and $J_{c r}$ are seepage gradients calculation and critical meanings.

According to the calculation results, it was acknowledged that maximum meaning of the seepage flow gradients developed from cracks, is 1.5 (Fig. 3). From this point starts disturbance of the seepage steadiness and beginning of suffusion.

Suffusion development causes pore increase in soil. Suffusion development model in time was accepted. Connection of the deformation modulus (E) with pores (n) function is presented with using decrease regularity curve $E_{y}=f(n)$ (Fig. 4). 


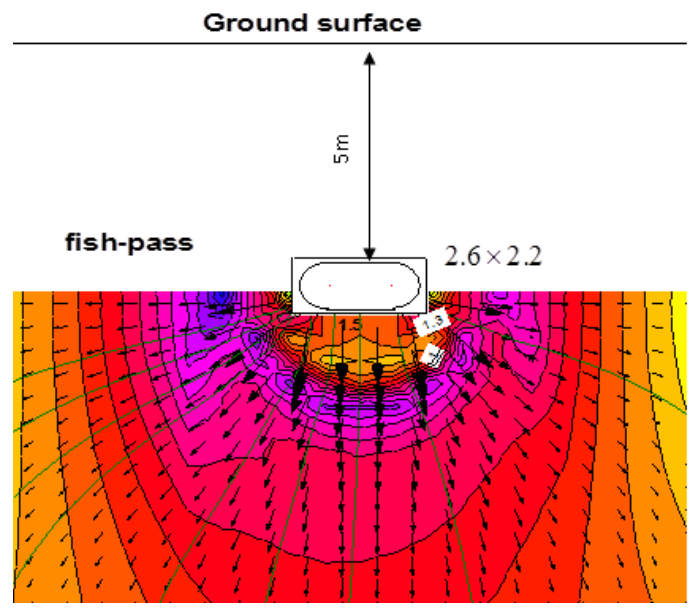

Fig. 3. Seepage gradients in fish-way foundation.

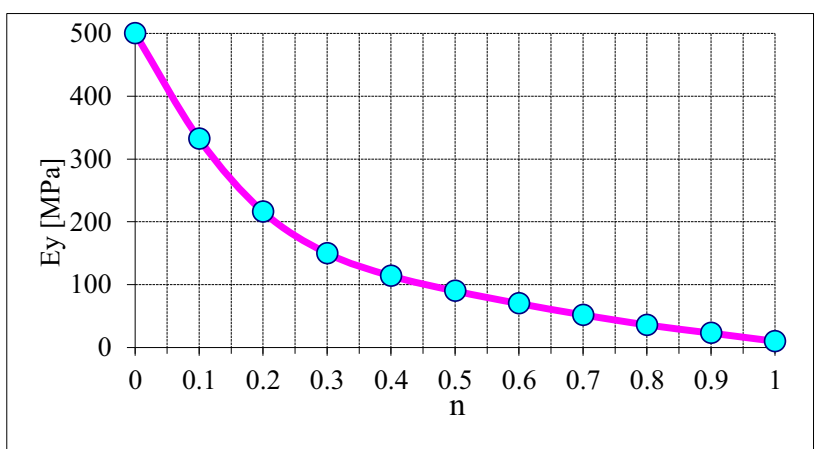

Fig. 4. $E_{y}=f(n)$ - reletionship between elastice modulus and pores.

\section{Deformation prosess in right bank foundation}

Estimation of deformation development processes in time in bank foundation was held with statistic calculation (cyclic-iteration sequence) using soil operation non-liner model [2]. Square is parametrical elements was used as an finite element mesh measurer. In zone of tensile zone and high compression, also in high seepage gradient zone element gains anisotropic properties. Anisotropic axis in element are orientated according to the main stress (Fig. 5).

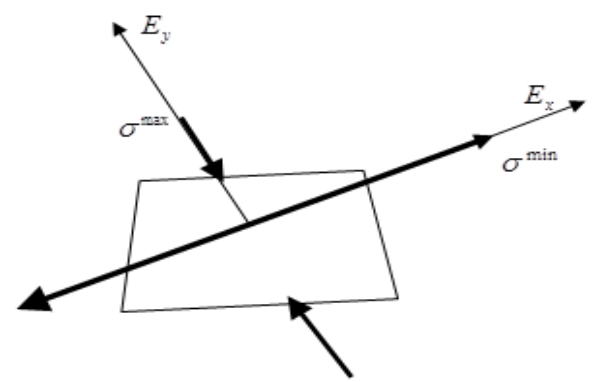

Fig. 5. Finite element anisotropic model. 
Deformation modulus values are corrected in the following way:

- in compressions direction - $\sigma=f(\varepsilon)$ according to the curve;

- in zone of high seepage gradients, according to the $E_{y}=f(n)$ curve (in the fish-way foundation)

- towards tensile stress direction - $E_{x} \approx 0$, when $\sigma \succ R$, where $R$ - generally, soil strength on expansion (zone of cracking behind concrete wall).

Calculation results showed that change of deformation modulus in fish-way foundation influences deformation development of bank (Fig. 6, 7). Under fish-way, in zone of high gradients, developed suffusion increased its settlement and cracks opening in fish-way construction. This causes increase suffusion. This means that crack development and suffusion causes inter-progressive development.

Y-Displacement vs. Y

a)
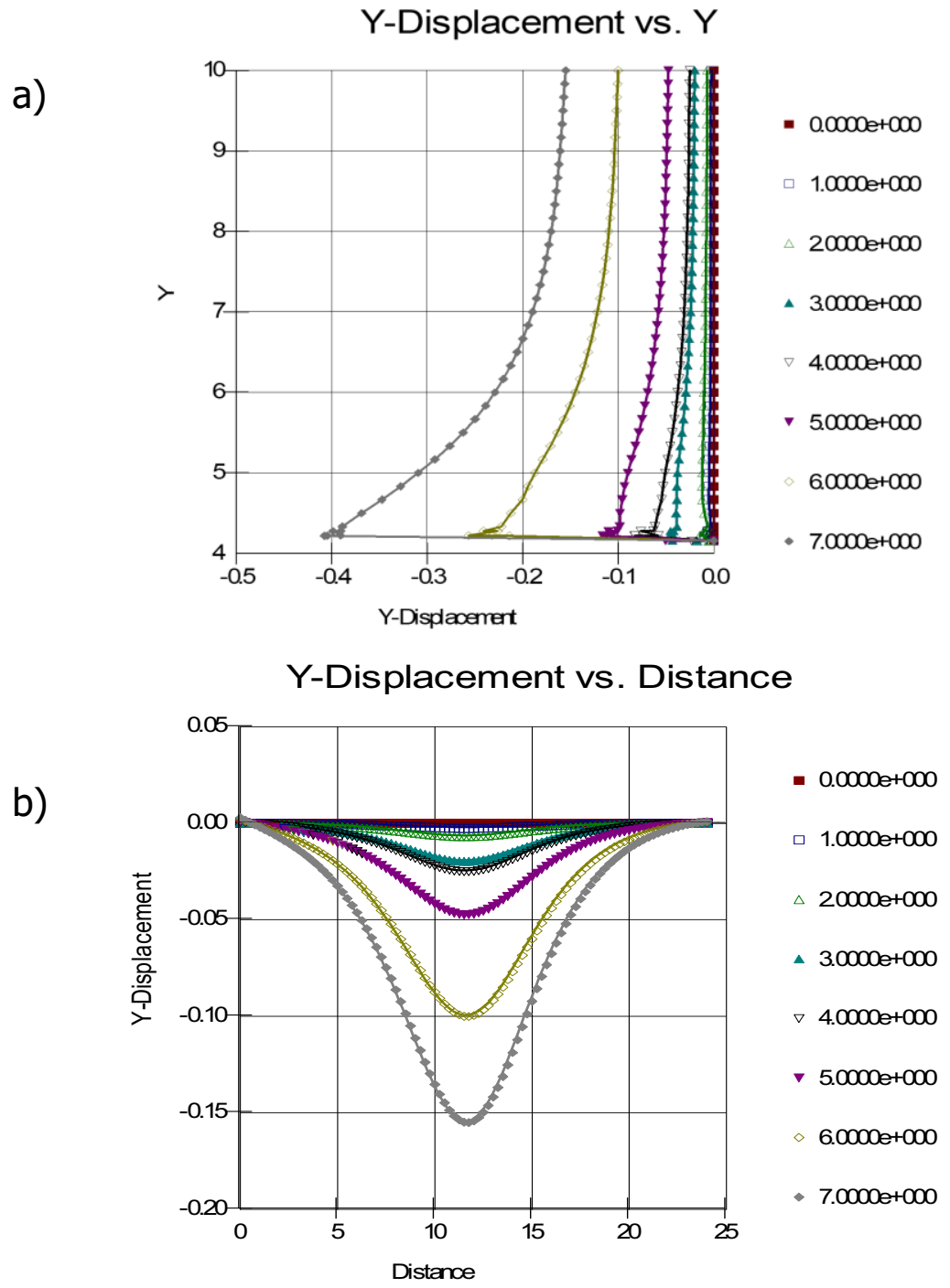

Fig. 6. Settlement developed in fish-way structures cross section:

a) in depth of embankment; b) embankment surface. 


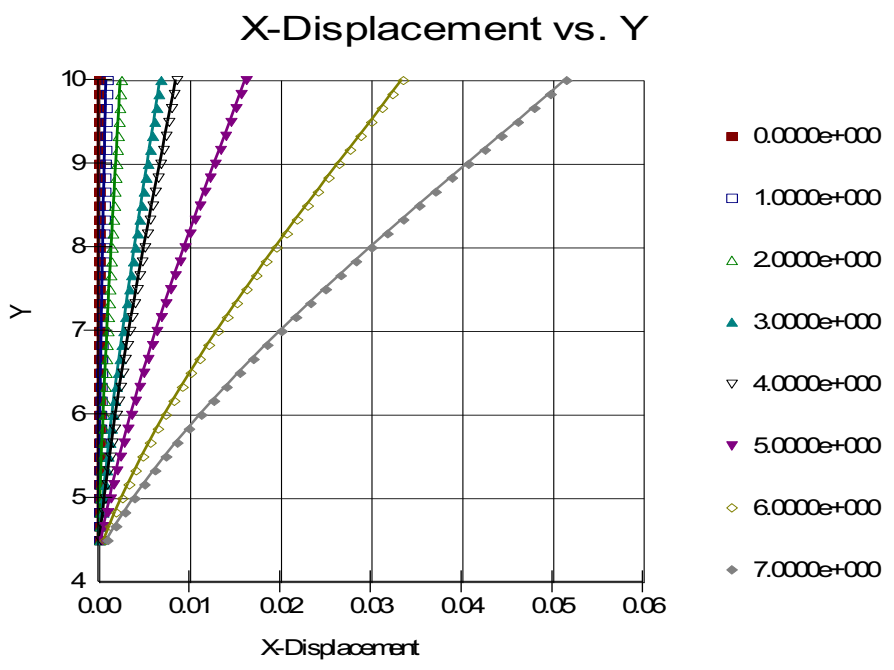

Fig. 7. Behind the wall crack development dynamic in depth of embankment.

Fish-way settlement (Fig. 6), developed caused soil replacement and gap open development in horizontal direction next cracking in bank foundation (it spread in depth down to 5.4 m, Fig. 7).

Within the cracks developed depth behind the concrete wall is loosing support, that causes increase tensile stress on its pressure surface. This itself causes lost of strength bearing capacity. Currently, bearing capacity is almost out. Increase of depth crack in soil will cause crack development in the wall herewith, hydraulic break-through and groundwater table rise

\section{Seepage parameters analasys in the right bank foundation}

Seepage parameters study were carried out in bank foundation using "fish-way - drainage foundation" system. Basic rock mass is presented with tuphogenic sand, but the bank foundation with $12 \mathrm{~m}$ capacity embankments with fish-way and drainage located there.

Hydraulic conductivity normative values (using the reference books and analogs) are:

- basic massive $K_{m} \approx 10^{-4} \mathrm{~cm} / \mathrm{sec}$;

- embankment $K_{E} \approx 1 \mathrm{~cm} / \mathrm{sec}$.

Hydraulic conductivity values was corrected during the iteration calculations. It was accepted that groundwater table elevation, in correspondence with piezometer measuring results, is satisfied for the $K_{E} / K_{m} \approx 4.5 \bullet 10^{5}$ value (Fig. 8).

Ratio $K_{0} / K_{m}{ }^{5}$ is quite big, consequently, basic massive and embankment contact is presented practically as a seepage outlet section. Groundwater table reaches to the highest elevation near the right bank wall, farther it slowly goes down.

On the first stage of the calculation, drainage wasn't foreseen. Drainage operation was studied separately, using classical solutions and finite elements method [3];

Lowered pressure in drainage gallery cross, made according to the classical solution, is defined with the formula [4]: 


$$
\varphi_{b}=\frac{1}{1+\frac{N \cdot r_{c}}{\pi}\left(\frac{1}{R+b}-\frac{1}{2 t}\right)}
$$

where: $N$ - quantity of bores in the drainage galleries, $r_{c}$ - bore radius, $R$ - radius of drainage galleries, $b$ - half distance between existing bores, $t$ - distance from the drainage center to the groundwater table elevation. $\varphi_{b}=0.96 \mathrm{~m}$ as calculated.

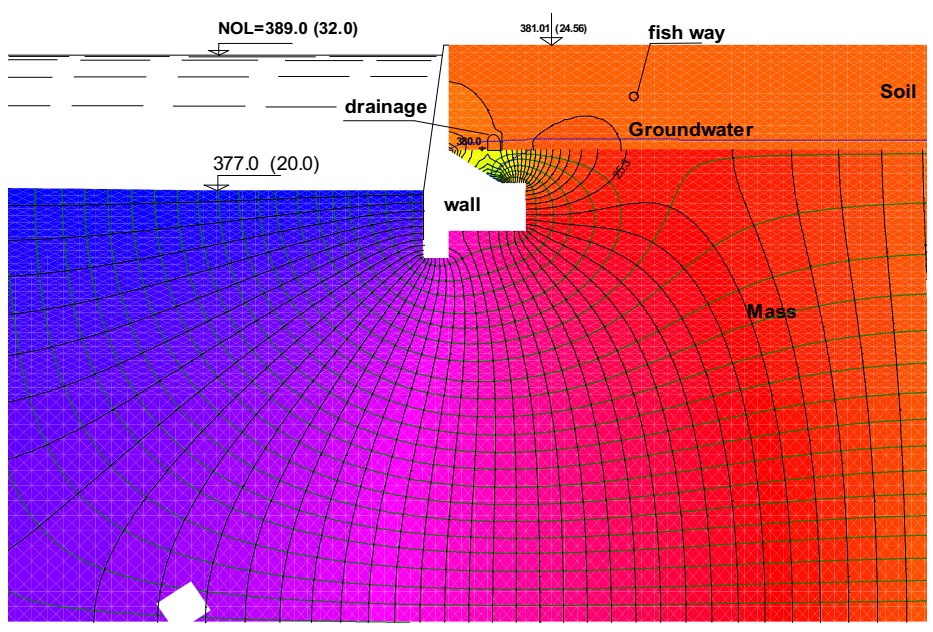

Fig. 8. Seepage head distribution in the "Fish-way - drainage - foundation" system.

By using finite element model, was defined that depression surface lowers till $100 \mathrm{~cm}$ in drainage cross (Fig. 9) that is in good compliance with the classic solution results.

Hence seepage is provided within the basic mass (tuphogenic sand rocks) and determines groundwater table level of the bank, and drainage is incapable to change seepage regime. It's maximum effectiveness can be estimated by the decrease of the seepage pressure on the bank wall not exceeding $1 \mathrm{~m}$. So drainage is actually ineffective.

Seepage gradient distribution along the wall tooth and its vertical surface characterizes significantly unequal and maximum meaning does not exceed $0.6 \mathrm{sm}$.

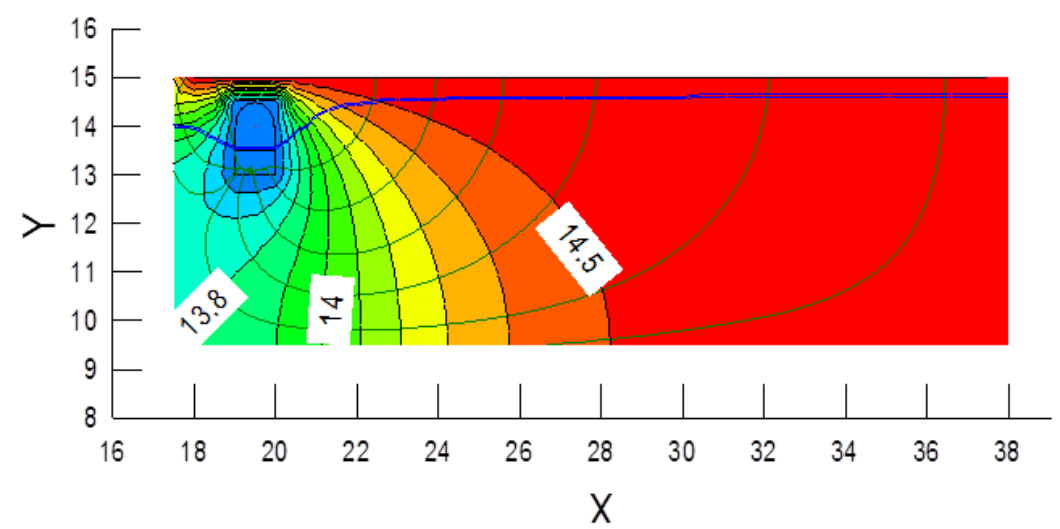

Fig. 9. Seepage head distribution in drainage. 


\section{Conclusions}

1. Mathematical models - "fish-way foundation", "retaining wall - drainage - foundation" was elaborated by the connected static and seepage scheme, that showed developed deformations and seepage regime in right bank foundation considering drainage in Ortachala HPP.

2. Because of the foundation basic mass and embankment hydraulic conductivity ratio high value, their contact surface appears as a seepage outlet section. So rock mass embankment contact surface defines the groundwater table elevation in bank foundation.

3. Drainage can't influence seepage regime (groundwater table elevation) development in the bank foundation. Drainage influence is spread only near the wall and decreases pressure on it within $1.0 \mathrm{~m}$. Thus, drainage can't be considered as a right decision for projecting.

4. Fish-way, that is located in the embankment undergo settlement, that was followed by crack development and seepage. Suffusion developed under the fish-way, in the zone of high gradients, increased its settlement and opened the cracks. This means, crack development and suffusion causes inter-progressive development.

5. Settlement, developed in fish-way structure lining, caused soil replacement towards horizontal direction relative to concrete retaining wall and depth crack development near the wall. Above mentioned increases tensile stress in wall and causes lost of strength bearing capacity. In the result, crack development in wall, will causes hydraulic breakthrough and groundwater table elevation rise in embankment - all inconvenient results connected to it.

6. Having established the cause of these processes, the fish way was stopped, and by result of which the fractures were stopped. So fish-way internal surface hydro isolation is necessary as a rehabilitation measure.

\section{References}

1. L. J. Segerlind, Applied Finite Element Analysis ( $2^{\text {nd }}$ Ed. John Wiley \& Sons Inc., New York, 1984)

2. O.C. Zienkiewicz, R. L Taylor, The Finite Element Method ( $5^{\text {th }}$ Ed. Vol. 1. Butterworth-Heinemann, Oxford, 2000)

3. P. Novak, A. I. B. Moffat, C. Nalluri, R. Narayanan, Hydraulic Structures $\left(4^{\text {th }}\right.$ Ed. Taylor \& Francis, London/New York, 2007)

4. Hydraulic Structures (Reference book, Moscow, 1983) 